\title{
Hot Corrosion of Ti-Re Alloys Fabricated by Selective Laser Melting
}

\author{
Kamil Majchrowicz ${ }^{1}$ (D) Zbigniew Pakieła ${ }^{1} \cdot$ Dorota Moszczyńska $^{1} \cdot$ \\ Tomasz Kurzynowski ${ }^{2} \cdot$ Edward Chlebus $^{2}$
}

Received: 1 March 2017/Revised: 30 November 2017/Published online: 18 December 2017

(C) The Author(s) 2017. This article is an open access publication

\begin{abstract}
Selective laser melting (SLM) is an additive manufacturing process that enables novel alloy production by combining metals with significantly different physical properties. In this paper, the hot corrosion behavior of Ti-Re alloys fabricated by SLM was studied in a mixture of $\mathrm{Na}_{2} \mathrm{SO}_{4}$ and $\mathrm{NaCl}$ salts at $600{ }^{\circ} \mathrm{C}$. The morphology and composition of the corrosion products were characterized by scanning electron microscopy with energy-dispersive X-ray spectroscopy and X-ray diffraction to understand the degradation mechanisms. It has been shown that the hot corrosion resistance of Ti-Re alloys was influenced by the chemical inhomogeneity of the oxide scale resulting from the presence of rhenium particles undissolved during the SLM process.
\end{abstract}

Keywords Ti-Re alloys $\cdot$ Selective laser melting $\cdot$ Hot corrosion $\cdot \mathrm{Na}_{2} \mathrm{SO}_{4}$ and $\mathrm{NaCl}$ salts

\section{Introduction}

Selective laser melting (SLM) is one of the rapid prototyping (RP) techniques for manufacturing nearly fully dense three-dimensional elements directly from CAD data. During the SLM process, thin metallic powder layers $(50-100 \mu \mathrm{m})$ are spread out on a building platform and subsequently fully melted and consolidated by a

Kamil Majchrowicz

kamil.majchrowicz@wimpw.edu.pl

1 Faculty of Materials Science and Engineering, Warsaw University of Technology, Wołoska 141, 02-507 Warsaw, Poland

2 Faculty of Mechanical Engineering, Centre for Advanced Manufacturing Technologies/ Fraunhofer Project Center, Wrocław University of Technology, Łukasiewicza 5, 50-371 Wrocław, Poland 
scanning laser beam. Building objects layer by layer allows 3D metal parts to be obtained [1-4]. SLM offers several advantages over the conventional manufacturing techniques such as reduction in processing steps, high material utilization and a near-net shape production of the geometrically complex shapes with a minimal machining [5, 6]. For these reasons, it is an attractive alternative to process difficultto-machine materials such as titanium and its alloys. Ti and its alloys are generally considered to be difficult-to-manufacture materials what results from the complexity of the extraction and melting processes and problems with their machining [6-8]. Thus, the SLM technology provides an ideal platform for a near-net shape production of $\mathrm{Ti}$ components instead of the highly time- and energy-consuming conventional multi-step processing techniques such as casting or powder metallurgy $[6,8]$.

Another important advantage of the SLM process is the ability to produce elements made of materials with high melting points, e.g., tantalum [9], molybdenum [10], rhenium [11] and tungsten carbide [12], and to combine metallic powders of those materials with metals of significantly different physical properties. As the attempts of modifying mechanical properties of Ti and its alloys in the SLM process by additions of refractory metals such as Mo [13] and Re [14] appeared successful, this work considers further investigations of selective laser melted Ti-Re alloys.

Titanium and titanium alloys are widely used in the aircraft industry; however, their temperature capability of up to $600{ }^{\circ} \mathrm{C}$ and relatively low wear resistance restrict their application for high-temperature parts of gas turbine engines [8, 15]. Due to the strong demand for reducing aircraft engine weight, the temperature and wear performance of Ti alloys need to be improved. Rhenium, as a refractory metal with excellent tensile and creep strength over a wide temperature range (up to $2000{ }^{\circ} \mathrm{C}$ ) and wear properties [16], seems to be highly effective in improving hightemperature durability of Ti alloys. So far, the papers concerning the effect of rhenium addition on $\mathrm{Ti}$ properties are limited [14, 17]. Chlebus et al. [14] and Kovtun and Ul'yanov [17] found that rhenium considerably increases hardness and strength of $\mathrm{Ti}$ at room temperature. Chlebus et al. [14] investigated the SLMprocessed Ti-Re alloys (0, 0.5, 1.0 and 1.5 at.\% Re) and reported that an addition of 1.5 at.\% Re improves hardness from 209 to $348 \mathrm{HV}$. Moreover, Ti-1.5 at.\% Re alloy fabricated by SLM exhibits significantly enhanced yield strength (YS) and ultimate tensile strength (UTS) of 1038 and $1162 \mathrm{MPa}$, respectively [14]. These values are very close to nickel-based superalloys used for advanced turbine engines with YS often in the range of 900-1300 MPa and UTS of 1200-1600 MPa [18]. However, it should be noted that SLM-processed materials are characterized by a strong anisotropy and high residual stresses after fabrication which affect their mechanical behavior [9, 19, 20]. Consequently, further studies of high-temperature mechanical properties of $\mathrm{Ti}-\mathrm{Re}$ alloys, taking into account the microstructure anisotropy and internal stresses, are needed for their comparison to Ni-based superalloys.

The improvement in temperature capability for $\mathrm{Ti}$ alloys also requires corrosion resistance enhancement. Aircraft engine parts are exposed to high-temperature oxidation and hot corrosion, defined as an accelerated high-temperature corrosion in 
the presence of salt contaminants such as $\mathrm{Na}_{2} \mathrm{SO}_{4}$ and $\mathrm{NaCl}[21,22]$. Kovtun and Ul'yanov [17] characterized the effect of rhenium on the oxidizability of titanium at $800{ }^{\circ} \mathrm{C}$. For low rhenium contents (up to $1 \mathrm{wt} \%$ ), the oxidation rate was slightly increased, whereas at higher content ( $3 \mathrm{wt} \% \mathrm{Re}$ ) it was considerably decreased, in comparison with Ti. They also established that rhenium impedes grain growth and diffusion of oxygen and nitrogen into the titanium. The hot corrosion resistance of Ti-Al alloys [23-25] and TiAl-based intermetallics [26-30] has been determined in numerous papers; however, there is a lack of information about Ti-Re alloys. Therefore, the present paper concerns the corrosion behavior of $\mathrm{Ti}-\mathrm{Re}$ alloys produced by SLM in the presence of $\mathrm{Na}_{2} \mathrm{SO}_{4}$ and $\mathrm{NaCl}$ salts. The obtained results establish the effect of rhenium on the corrosion properties of titanium alloys.

\section{Experimental Procedures}

The titanium (SLM-Ti), Ti-2Re, Ti-4Re and $\mathrm{Ti}-6 \mathrm{Re}$ (compositions are given in wt\%) samples used in this study were produced by the SLM process from mixtures of titanium and rhenium powders. Test specimens were fabricated using the SLM Realizer II (MCP-HEK) machine with the following parameters: laser power $400 \mathrm{~W}$, scanning speed $1000 \mathrm{~mm} / \mathrm{s}$, scanning time of one point $60 \mu \mathrm{s}$, distance between scanning points $60 \mu \mathrm{m}$, layer thickness $50 \mu \mathrm{m}$, distance between scanning lines $100 \mu \mathrm{m}$ and energy density $80 \mathrm{~J} / \mathrm{mm}^{3}$.

The specimens for hot corrosion tests, with dimension of about $9 \times 9 \times 2 \mathrm{~mm}$, were cut out from SLM manufactured cuboids. The orientation of samples with respect to the building direction is shown in Fig. 1. The microstructure of as-built specimens on the $Y Z$ plane is presented in Fig. 2. The martensitic $\alpha^{\prime}$ microstructure was revealed in the case of SLM-Ti. There were no signs of its directional solidification. On the contrary, the microstructure of Ti-Re alloys was dominated by columnar prior $\beta$ grains (with a width of 20-50 $\mu \mathrm{m}$ and length of several hundreds of microns) which were slightly deflected from the building direction ( $Z$-axis). Each columnar grain showed fine martensitic microstructure.

Before exposure, all surfaces of hot corrosion samples were ground with $\mathrm{SiC}$ papers down to 1200 grit and cleaned ultrasonically in acetone, followed by drying in hot air. Specimens were inserted into the quartz crucibles and immersed in the mixture of $75 \mathrm{wt} \% \mathrm{Na}_{2} \mathrm{SO}_{4}+25 \mathrm{wt} \% \mathrm{NaCl}$ salts which is a common environment for hot corrosion tests [28-33]. Besides, the presence of chloride ions facilitates the hot corrosion attack of Ti-based alloys and promotes oxide-scale cracking [23, 24, 30]. According to Gonzalez-Rodriguez et al. [34], the salt mixture in an amount equivalent to $500 \mathrm{mg} / \mathrm{cm}^{2}$ was used to cover samples completely. The immersion method was chosen based on results obtained by Zhang et al. [27]. They investigated three different exposure methods: specimens suspended in salt vapor, deposited with a salt film and immersed completely in molten salt. The immersion method resulted in the severest hot corrosion of Ti-based alloys, and thus, it has been implemented in this study. Hot corrosion tests were performed in a laboratory furnace at $600{ }^{\circ} \mathrm{C}$ for $5,15,25,50$ and $100 \mathrm{~h}$. Each exposure time was represented by one specimen. After exposure, the samples were cleaned with boiling water to 


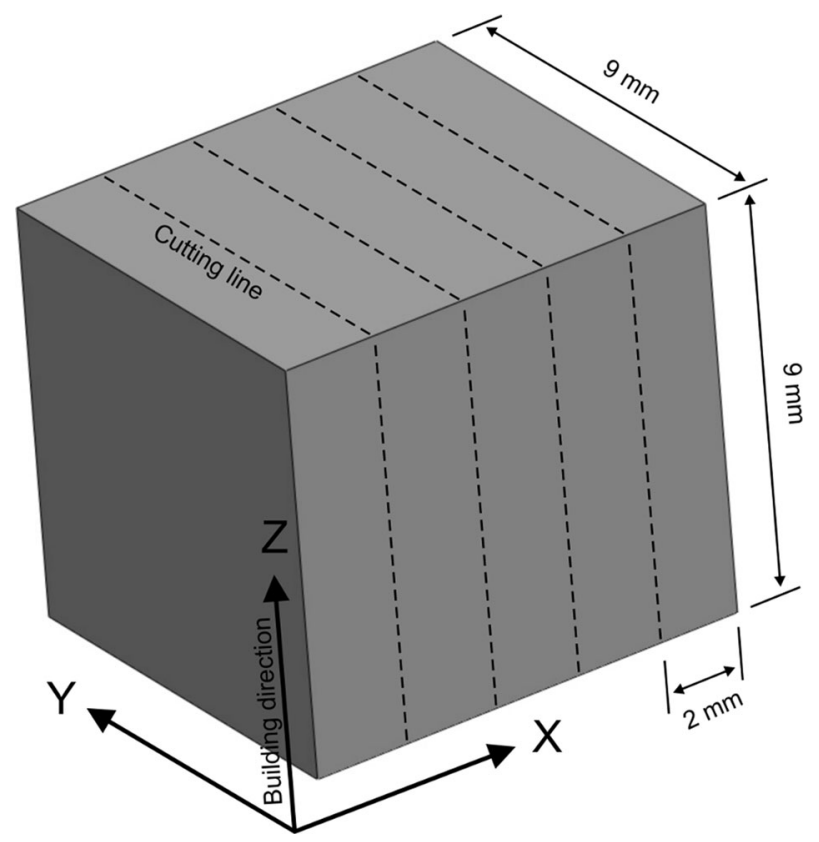

Fig. 1 Building orientation of hot corrosion test specimens

dissolve the remains of $\mathrm{Na}_{2} \mathrm{SO}_{4}$ and $\mathrm{NaCl}$ salts. The mass of each specimen before and after exposure was measured using an electronic balance with an accuracy of $\pm 0.1 \mathrm{mg}$.

After the corrosion tests, the phase composition of the samples was determined by X-ray diffraction using Bruker AXS D8 Discover diffractometer with $\mathrm{Cu} \mathrm{K}_{\alpha}$ radiation $(\lambda=1.54 \AA)$. The morphology and chemical composition of the specimens after the corrosion test were analyzed on the surface (top view) and on transversal cross sections by scanning electron microscope (SEM) Hitachi SU-8000 equipped with an energy-dispersive spectroscope (EDS). To determine the quantity of undissolved rhenium particles, computed tomography (XCT) measurements were performed on a Metrotom 1500 CT machine with the following parameters: voltage of X-ray source $180 \mathrm{kV}$, current $100 \mu \mathrm{A}$, exposure time $2000 \mathrm{~ms}$ and voxel size $18.87 \mu \mathrm{m}$. The obtained data were processed with Volume Graphics VG Studio Max 2.0 software. Details and possibilities of XCT measurements have been explained in [35].

\section{Results}

\section{Hot Corrosion Resistance}

The weight loss per unit area of the SLM-Ti-Re alloys as a function of the exposure time in the mixture of $\mathrm{Na}_{2} \mathrm{SO}_{4}$ and $\mathrm{NaCl}$ salts at $600{ }^{\circ} \mathrm{C}$ is shown in Fig. 3. The 



Fig. 2 Microstructure of as-built Ti-Re alloys on the YZ plane: a SLM-Ti, b Ti-2Re, c Ti-4Re and d Ti-6Re

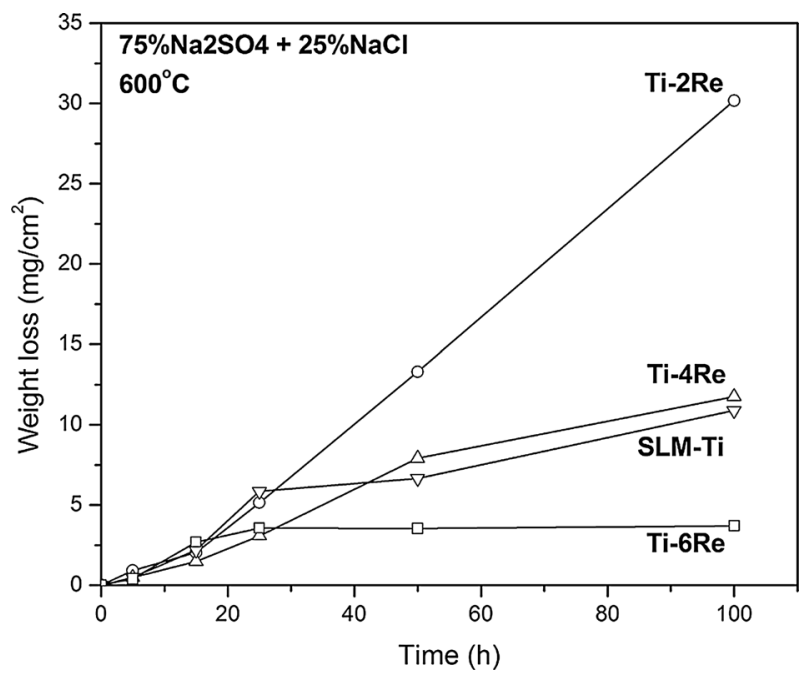

Fig. 3 Weight loss versus time of exposure of SLM-Ti, Ti-2Re, Ti-4Re, Ti-6Re alloys in the mixture of $\mathrm{Na}_{2} \mathrm{SO}_{4}$ and $\mathrm{NaCl}$ salts at $600{ }^{\circ} \mathrm{C}$ 
corrosion kinetics indicate that rhenium addition affects titanium hot corrosion behavior significantly. Ti-2Re exhibited the poorest corrosion resistance, with a strong tendency of scale spallation, following almost linear kinetics of corrosion. The final mass loss after $100 \mathrm{~h}$ of exposure was about $30 \mathrm{mg} / \mathrm{cm}^{2}$. SLM-Ti and Ti4Re showed similar corrosion resistance resulting in the weight loss of 10.89 and $11.75 \mathrm{mg} / \mathrm{cm}^{2}$ after $100 \mathrm{~h}$, respectively. Minor scale spallation occurred for Ti-6Re samples followed by the lowest mass change. At the beginning of hot corrosion tests (after $25 \mathrm{~h}$ ), Ti-6Re samples lost about $3.5 \mathrm{mg} / \mathrm{cm}^{2}$, and then, their weight remained stable. According to the obtained results, the hot corrosion resistance of SLM-processed Ti-Re alloys in the mixture of $\mathrm{Na}_{2} \mathrm{SO}_{4}$ and $\mathrm{NaCl}$ salts increases in the order: $\mathrm{Ti}-2 \mathrm{Re}<\mathrm{Ti}-4 \mathrm{Re}<\mathrm{SLM}-\mathrm{Ti}<\mathrm{Ti}-6 \mathrm{Re}$.

\section{Phase Composition of Corrosion Products}

X-ray diffraction patterns for Ti-Re samples annealed in the mixture of $\mathrm{Na}_{2} \mathrm{SO}_{4}$ and $\mathrm{NaCl}$ salts at $600{ }^{\circ} \mathrm{C}$ for different times are shown in Fig. 4. All peaks were normalized to a major peak. The $\alpha$-Ti phase was identified as a substrate material phase since the martensitic $\alpha^{\prime}$ microstructure is characteristic for commercially pure Ti fabricated by SLM [14, 36] (as shown in Fig. 2). The main corrosion products were identified as $\mathrm{TiO}_{2}$ (rutile), $\mathrm{Na}_{2} \mathrm{Ti}_{5} \mathrm{O}_{12}$ and $\mathrm{Ti}_{0.625} \mathrm{~S}$. Weak reflections from pure
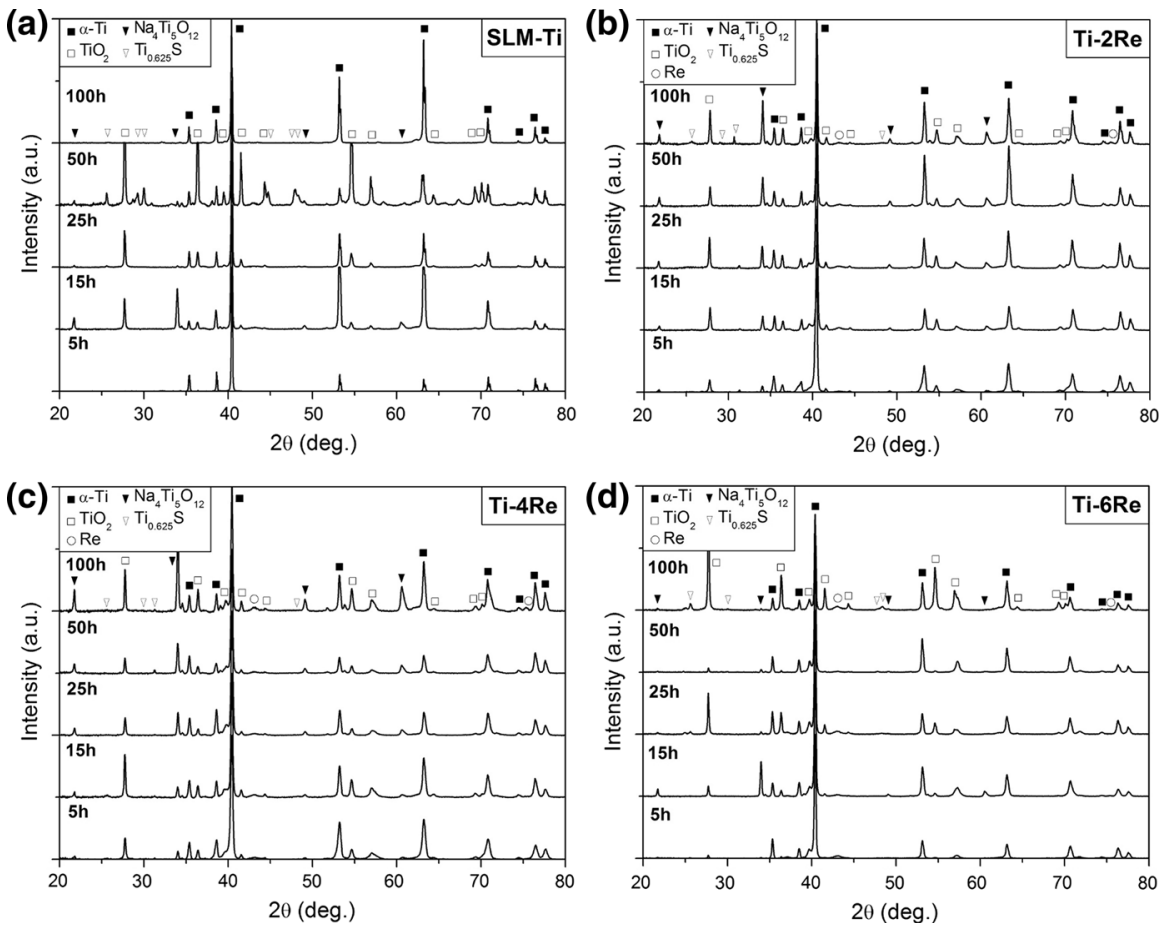

Fig. 4 X-ray diffraction patterns of a SLM-Ti, b Ti-2Re, $\mathbf{c}$ Ti-4Re and $\mathbf{d}$ Ti-6Re after exposure in the mixture of $\mathrm{Na}_{2} \mathrm{SO}_{4}$ and $\mathrm{NaCl}$ salts at $600{ }^{\circ} \mathrm{C}$ for $5,15,25,50$ and $100 \mathrm{~h}$ 
rhenium were revealed for Ti-Re alloys (Fig. 4b-d) which indicate the presence of undissolved rhenium particles near the substrate surface. For SLM-Ti after exposure for $5 \mathrm{~h}$, the only observed peaks corresponded to $\alpha$-Ti phase. The peaks from hot corrosion products were noticed for longer times. However, after $100 \mathrm{~h}$ of exposure almost the entire oxide scale spalled off indicating weak adhesion of $\mathrm{TiO}_{2}$ to the titanium substrate. In the case of Ti-Re alloys, there is no significant change in the corrosion products with changing rhenium addition. $\mathrm{TiO}_{2}, \mathrm{Na}_{2} \mathrm{Ti}_{5} \mathrm{O}_{12}$ and weak $\mathrm{Ti}_{0.625} \mathrm{~S}$ peaks were observed in almost every sample. The only difference was the peak intensities indicating slightly different volume fraction of corrosion products in each sample. The presence of corrosion products after $100 \mathrm{~h}$ of exposure suggests stronger adhesion of the oxide scale to Ti-Re substrates in comparison with SLMTi.

\section{Morphology and Chemical Composition of Corrosion Products}

After hot corrosion tests in the mixture of $\mathrm{Na}_{2} \mathrm{SO}_{4}$ and $\mathrm{NaCl}$ salts, steel-colored scale appeared on the samples' surfaces. Micrograph in Fig. 5a shows fine needleshaped crystals identified by EDS analysis as $\mathrm{TiO}_{2}$. Similar structure was obtained by Godlewska et al. [28]. As the time of exposure increased, those crystals grew into round-shaped structures and led to thick oxide-scale formation (Fig. 5b). After hot corrosion for $100 \mathrm{~h}$, the scale thickness on Ti-Re alloys did not exceed $50 \mu \mathrm{m}$. In all investigated samples, the scale was brittle with relatively poor adhesion to the substrate and many visible cracks propagating in both parallel and transverse directions to the sample surface.

Chemical analysis by EDS revealed that the scale consisted mainly of $\mathrm{Ti}, \mathrm{O}, \mathrm{Na}$ and S. Figure 6 shows the map distribution of selected elements on the cross section of Ti-Re alloys after hot corrosion for $100 \mathrm{~h}$. According to XRD, the scale formed on the surface was a mixture of $\mathrm{TiO}_{2}, \mathrm{Na}_{2} \mathrm{Ti}_{5} \mathrm{O}_{12}$ and $\mathrm{Ti}_{0.625} \mathrm{~S}$. The results presented in Fig. 6 confirm the XRD data. The scale consists mainly of titanium dioxide and sodium titanate. Moreover, it is clearly visible that sulfur has diffused through the scale and formed titanium sulfide between the substrate and titanium oxide scale. The cross-sectional observations revealed the presence of undissolved rhenium
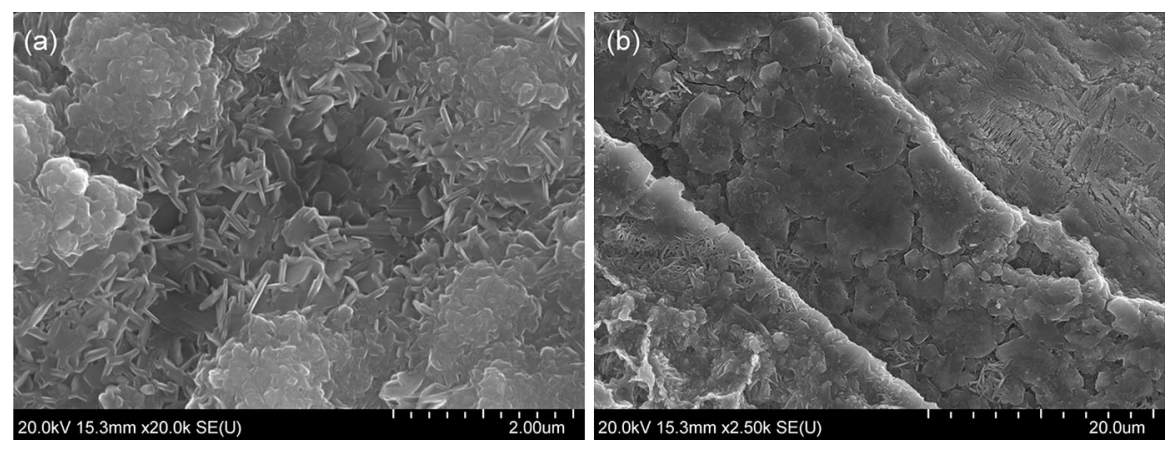

Fig. 5 Surface morphology of Ti-2Re after hot corrosion test in the mixture of $\mathrm{Na}_{2} \mathrm{SO}_{4}$ and $\mathrm{NaCl}$ salts at $600{ }^{\circ} \mathrm{C}$ for: a 15 and b $50 \mathrm{~h}$ 




Fig. 6 EDS analysis results for Ti-Re alloys after hot corrosion test in the mixture of $\mathrm{Na}_{2} \mathrm{SO}_{4}$ and $\mathrm{NaCl}$ salts at $600{ }^{\circ} \mathrm{C}$ for $100 \mathrm{~h}$

particles (marked with arrows in Fig. 6). The higher local concentration of rhenium within the outer scale was also observed suggesting rhenium outward diffusion from Ti-Re substrates. However, the outward diffusion of rhenium seems to be highly unlikely at $600{ }^{\circ} \mathrm{C}$ for such short time exposures. Even during hot corrosion tests of $\mathrm{Ti}-47 \mathrm{Al}-1 \mathrm{Re}-1 \mathrm{~W}-0.2 \mathrm{Si}$ (at.\%) at $750-800{ }^{\circ} \mathrm{C}$ for longer times, rhenium outward diffusion was not observed [37]. Rhenium is a very heavy slow-diffusing element [38] as shown by Zeng et al. [39] and Zhang et al. [40] for nickel and nickel-based superalloys. Therefore, the observed phenomenon has to be associated with the presence of undissolved Re particles at this particular location.

Nevertheless, SEM and EDS analysis of the corroded surfaces (top view) confirmed the occurrence of regions with higher local Re concentration as presented 

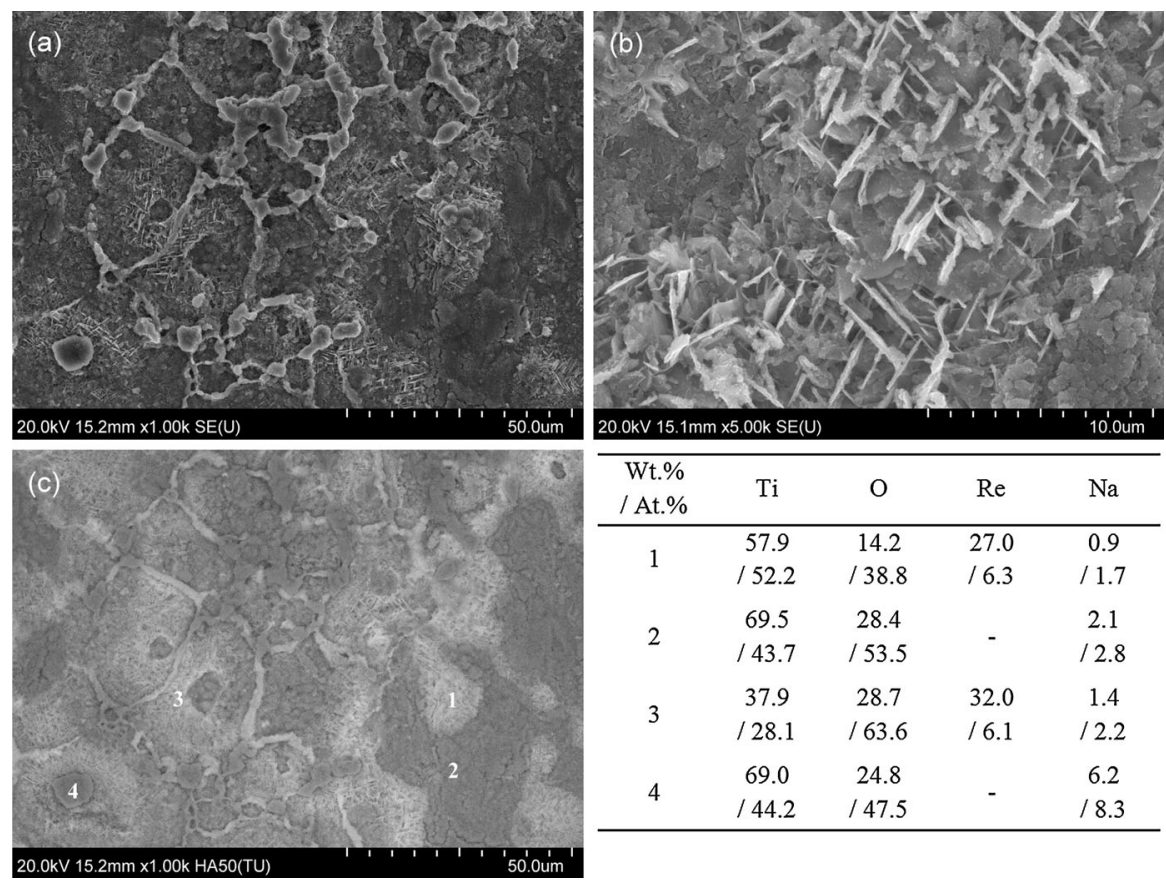

\begin{tabular}{ccccc}
\hline $\begin{array}{r}\text { Wt.\% } \\
\text { / At.\% }\end{array}$ & $\mathrm{Ti}$ & $\mathrm{O}$ & $\mathrm{Re}$ & $\mathrm{Na}$ \\
\hline \multirow{2}{*}{1} & 57.9 & 14.2 & 27.0 & 0.9 \\
& $/ 52.2$ & $/ 38.8$ & $/ 6.3$ & $/ 1.7$ \\
& 69.5 & 28.4 & & 2.1 \\
2 & $/ 43.7$ & $/ 53.5$ & - & $/ 2.8$ \\
& 37.9 & 28.7 & 32.0 & 1.4 \\
3 & $/ 28.1$ & $/ 63.6$ & $/ 6.1$ & $/ 2.2$ \\
& 69.0 & 24.8 & & 6.2 \\
4 & $/ 44.2$ & $/ 47.5$ & - & $/ 8.3$ \\
\hline
\end{tabular}

Fig. 7 a, b Surface morphology of Ti-2Re after hot corrosion test in the mixture of $\mathrm{Na}_{2} \mathrm{SO}_{4}$ and $\mathrm{NaCl}$ salts at $600{ }^{\circ} \mathrm{C}$ for $100 \mathrm{~h}$; c mass contrast image of area corresponding to (a) with the results of EDS analysis in marked points

in Fig. 7. The rhenium "clusters" were observed on the surface of the outer scale showing needle-shaped morphology, as shown in Fig. 7b. Based on SEM micrographs taken in mass contrast (Fig. 8), the area fraction of rhenium clusters to overall surface area of the oxide scale was estimated for Ti-Re alloys after hot corrosion for $100 \mathrm{~h}$. The calculated values are summarized in Table 1. It should be noted that the regions of higher Re concentration were distributed homogenously on the oxide-scale surface of $\mathrm{Ti}-\mathrm{Re}$ alloys. However, some agglomerations of Re clusters were also observed in the case of Ti-2Re alloy (as shown in Fig. 7). The highest area fraction of Re clusters exhibited Ti-2Re showing the value of $2.42 \%$ (Fig. 8a). Surprisingly, the amount of Re clusters decreased with increasing rhenium content in Ti-Re alloys. Noteworthy is the fact that there were almost no regions of higher Re concentration in Ti-6Re (Fig. 8c).

\section{Degree of Undissolved Rhenium Particles}

The XRD and EDS analysis revealed the presence of undissolved rhenium particles. According to the $\mathrm{Ti}-\mathrm{Re}$ phase diagram [41], the solubility of $\mathrm{Re}$ in $\alpha$-Ti is approximately 0.1 at. $\%$ at $750{ }^{\circ} \mathrm{C}$, in $\alpha+\beta$ two-phase region is between 0.1 and 10 at. $\%$, while in $\beta$-Ti it reaches 40 at.\%. Liquid titanium readily dissolves rhenium; however, the presence of some larger Re particles in the powders mixture 

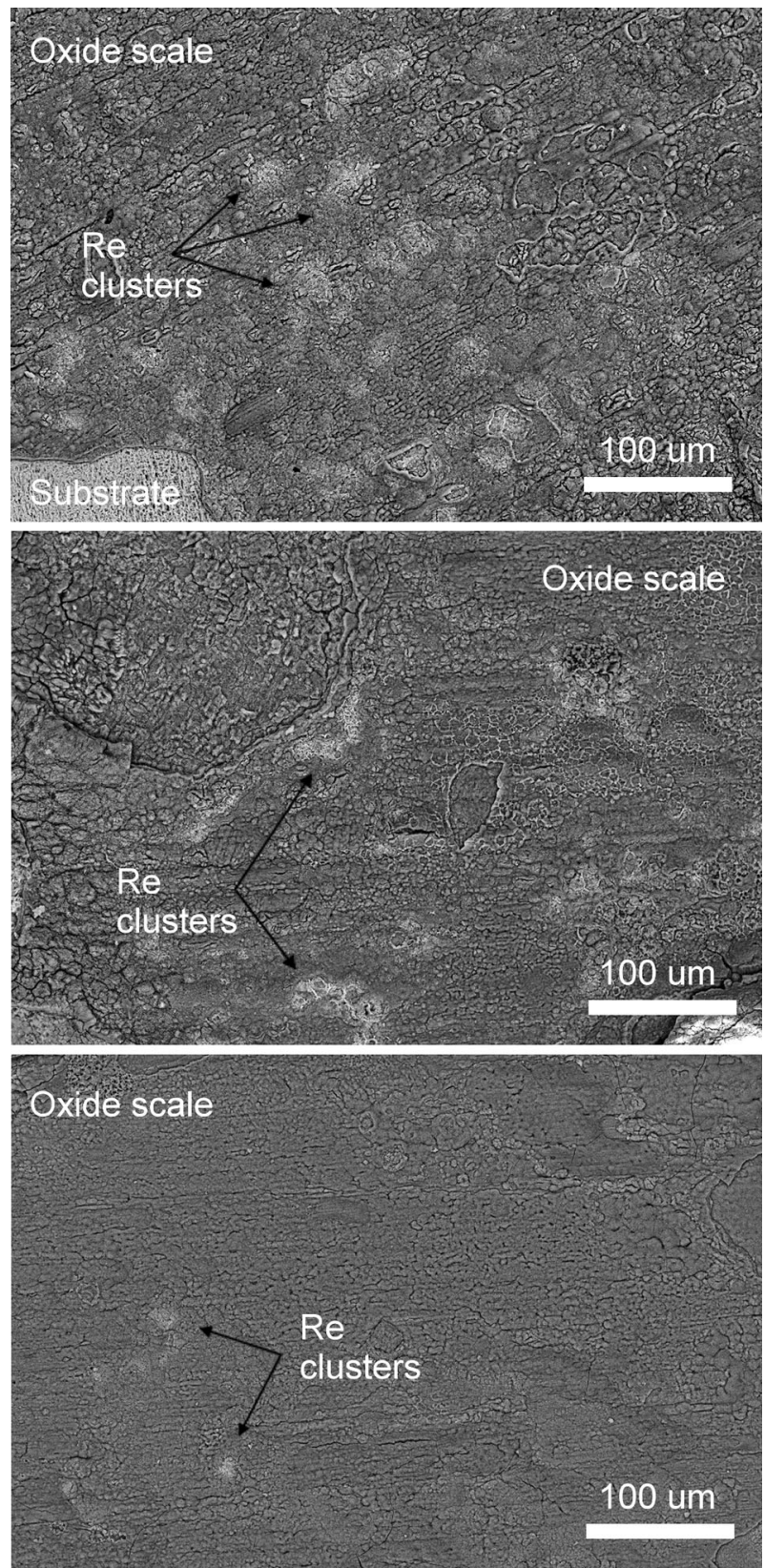

Fig. 8 Mass contrast images of oxide scales formed on Ti-Re alloys: a Ti-2Re, b Ti-4Re and $\mathbf{c} \mathrm{Ti}-6 \mathrm{Re}$

increases the risk of incomplete rhenium dissolution due to the insufficient energy density of scanning laser beam [14]. Therefore, to determine the degree of rhenium dissolution by the SLM process, computed tomography measurements were 
Table 1 Summary of rhenium clusters and undissolved rhenium particles measurements

\begin{tabular}{lllc}
\hline Material & Ti-2Re & Ti-4Re & Ti-6Re \\
\hline Area fraction of Re clusters (\%) & 2.42 & 0.44 & $<0.1$ \\
Volume fraction of undissolved Re particles (\%) & 0.15 & 0.07 & 0.09 \\
\hline
\end{tabular}

performed. The summary of obtained results for Ti-2Re, Ti-4Re and Ti-6Re is shown in Table 1. The highest calculated volume fraction of undissolved rhenium particles, equal to $0.15 \%$, was observed in Ti-2Re. Ti-4Re and Ti-6Re were characterized by lower degree of undissolved rhenium, i.e., 0.07 and $0.09 \%$, respectively.

\section{Discussion}

Hot corrosion of Ti-Re alloys in the mixture of $\mathrm{Na}_{2} \mathrm{SO}_{4}$ and $\mathrm{NaCl}$ salts at $600{ }^{\circ} \mathrm{C}$ leads to the formation of non-protective $\mathrm{TiO}_{2}$ (rutile) scale which spalls off easily $[23,24,27]$. As the exposure time is extended, the oxide scale gets thicker and starts to spalls off after reaching a certain thickness as shown for SLM-Ti after $100 \mathrm{~h}$. However, the presence of corrosion products in Ti-Re alloys after the same exposure time suggests the stronger adhesion of the oxide scale to the substrates in comparison with pure titanium. Considering the coefficients of linear thermal expansion (CTE) for $\mathrm{Ti}$ and $\mathrm{TiO}_{2}$, presented in Table 2, some mismatch is clearly observed. The pure titanium has higher CTE than rutile $\left(9.7\right.$ and $8.19 \times 10^{-6}{ }^{\circ} \mathrm{C}^{-1}$, respectively) indicating the possibility of oxide-scale cracking and spallation. As rhenium has a low coefficient of thermal expansion, Kovtun and Ul'yanov [17] found that alloying titanium with Re decreases the CTE and for Ti-3 wt\% Re alloy is about $8.2 \times 10^{-6}{ }^{\circ} \mathrm{C}^{-1}$. Those results clarify that the rhenium addition reduces the mismatch of CTE between $\mathrm{TiO}_{2}$ and Ti-Re and can lead to better oxide-scale adhesion.

As the scale formed on Ti-Re alloys predominantly consists of $\mathrm{TiO}_{2}$, possible reactions of rutile with corrosion salts have to be considered. According to [44], the following reaction of sodium sulfate at high temperatures can be given as:

Table 2 The coefficients of linear thermal expansion (CTE) of $\mathrm{TiO}_{2}, \mathrm{Ti}, \mathrm{Re}$ and $\mathrm{Ti}-3 \mathrm{wt} \% \mathrm{Re}$

\begin{tabular}{llrl}
\hline Material & $\mathrm{CTE}\left(\alpha \times 10^{-6} /{ }^{\circ} \mathrm{C}\right)$ & Temperature range $\left({ }^{\circ} \mathrm{C}\right)$ & References \\
\hline $\mathrm{TiO}_{2}$ (rutile) & 8.19 & $0-500$ & {$[42]$} \\
$\mathrm{Ti}$ & 9.7 & $0-600$ & {$[43]$} \\
$\mathrm{Re}$ & $6.6(7.29)$ & $0-100(2000)$ & {$[43]$} \\
$\mathrm{Ti}-3 \mathrm{wt} \% \mathrm{Re}$ & 8.2 & $0-400$ & {$[17]$} \\
\hline
\end{tabular}




$$
\mathrm{Na}_{2} \mathrm{SO}_{4} \rightarrow \mathrm{Na}_{2} \mathrm{O}+\mathrm{SO}_{3}
$$

It is reported that $\mathrm{Na}_{2} \mathrm{O}$ tends to react with rutile and form sodium titanate $[23,31,33]$ which could be presented in this case as:

$$
\mathrm{Na}_{2} \mathrm{O}+5 \mathrm{TiO}_{2} \rightarrow \mathrm{Na}_{2} \mathrm{Ti}_{5} \mathrm{O}_{12}
$$

This explains the presence of a significant amount of sodium titanate according to XRD patterns obtained for all Ti-Re alloys (Fig. 4). Besides, as a rapid diffusion of $\mathrm{Na}^{+}$ions through rutile toward the substrate is expected [31, 33], the presence of sodium compounds within the oxide scale (Fig. 6) is fully reasonable.

With sodium chloride present in the test environment, the reaction of $\mathrm{TiO}_{2}$ with chloride ions forming volatile $\mathrm{TiCl}_{2}$ is also possible $[23,25]$. The $\mathrm{TiCl}_{2}$ dissociates at elevated temperatures to titanium and chloride ions. $\mathrm{Ti}^{2+}$ ions form a nonprotective $\mathrm{TiO}_{2}$ scale, whereas $\mathrm{Cl}^{-}$ions penetrate through cracks in the oxide scale and react with substrate to form another volatile chloride. The sequence of aforementioned reactions can be given as:

$$
\begin{gathered}
\mathrm{TiO}_{2}+2 \mathrm{Cl}^{-} \rightarrow \mathrm{TiCl}_{2}+2 \mathrm{O}^{2-} \\
\mathrm{TiCl}_{2} \rightarrow \mathrm{Ti}^{2+}+2 \mathrm{Cl}^{-} \\
\mathrm{Ti}^{2+}+2 \mathrm{O}^{2-} \rightarrow \mathrm{TiO}_{2}
\end{gathered}
$$

It has been reported [23, 24, 26, 28] that the formation of volatile chlorides results in increased oxide-scale porosity and leads to accelerated hot corrosion of Tibased alloys.

Another corrosion product formed during exposure in the mixture of $\mathrm{Na}_{2} \mathrm{SO}_{4}$ and $\mathrm{NaCl}$ salts at $600{ }^{\circ} \mathrm{C}$ was identified as titanium sulfide. The sulfide formation is a result of a reaction between sulfur from $\mathrm{Na}_{2} \mathrm{SO}_{4}$ and titanium substrate. It can occur as a result of sulfur diffusion through cracks to the scale/substrate interface. The low $\mathrm{O}_{2}$ potential in this region favors the sulfides formation [45]. The observed sulfur segregation at the scale/substrate interface (Fig. 6) can lead to easier spallation of corrosion products and accelerated degradation of substrate [32].

The results of phase identification did not reveal any effect of rhenium addition on the corrosion products formed during high-temperature exposure in the mixture of $\mathrm{Na}_{2} \mathrm{SO}_{4}$ and $\mathrm{NaCl}$ salts. However, SEM and EDS analysis showed regions of higher local Re concentration (Fig. 7). Surprisingly, the amount of rhenium clusters decreased with increasing Re content in Ti-Re alloys which could be explained in terms of the number of undissolved rhenium particles (Table 1). The highest surface area fraction of Re clusters was observed for $\mathrm{Ti}-2 \mathrm{Re}$ characterized by the biggest volume fraction of undissolved rhenium particles. The presence of regions with higher Re concentration leads to chemical inhomogeneity of the oxide scale and, as a consequence, to pit formation. It has been reported that rhenium exhibits a higher standard potential than titanium [46] and is characterized by a lower corrosion rate in $\mathrm{NaCl}$ environment $[47,48]$. The formation of pits in $\mathrm{Ti}-2 \mathrm{Re}$ and $\mathrm{Ti}-4 \mathrm{Re}$ alloys in the vicinity of Re clusters results in enhanced oxide-scale degradation and higher 
weight loss during hot corrosion tests (Fig. 3). Since the number of identified Re clusters (Table 1) and mass losses during hot corrosion tests (Fig. 3) show the same tendency with respect to rhenium content, it could be concluded that the fluctuations of chemical composition of the oxide scale have a decisive influence on corrosion resistance of $\mathrm{Ti}-\mathrm{Re}$ alloys.

The aforementioned results lead to the conclusion that the absence of rhenium clusters on the corroded surfaces of $\mathrm{Ti}-6 \mathrm{Re}$ alloy results in the enhanced hot corrosion resistance in comparison with pure titanium. The corrosion resistance at high temperatures is improved mainly by better adhesion of the oxide scale to the substrate due to the lower mismatch between the coefficients of thermal expansion of $\mathrm{TiO}_{2}$ and Ti-6Re alloy.

\section{Conclusions}

The hot corrosion behavior of titanium and Ti-Re alloys fabricated by SLM in the mixture of $\mathrm{Na}_{2} \mathrm{SO}_{4}$ and $\mathrm{NaCl}$ salts at $600{ }^{\circ} \mathrm{C}$ was investigated. It was observed that the hot corrosion resistance of $\mathrm{Ti}-\mathrm{Re}$ alloys increased in the order: $\mathrm{Ti}-2 \mathrm{Re}<\mathrm{Ti}-$ 4Re $<$ SLM-Ti $<\mathrm{Ti}-6 \mathrm{Re}$. The high-temperature exposure in salt environment caused the formation of non-protective $\mathrm{TiO}_{2}$ scale which was cracked and porous due to the formation of volatile chlorides. The sodium titanate $\mathrm{Na}_{2} \mathrm{Ti}_{5} \mathrm{O}_{12}$ formation, as a result of $\mathrm{Na}_{2} \mathrm{O}$ with rutile reaction, was also identified. The hot corrosion resistance of $\mathrm{Ti}-\mathrm{Re}$ alloys was influenced by rhenium clusters present on the corroded surfaces. The chemical inhomogeneity of the oxide scale results from the presence of undissolved rhenium particles what leads to enhanced scale degradation. Therefore, full rhenium particles dissolution is essential to improve corrosion resistance of titanium by rhenium addition.

Acknowledgements This research was financially supported by the National Centre for Research and Development within RenMaTecH project (Contract No. PBS1/A5/12/2012).

Open Access This article is distributed under the terms of the Creative Commons Attribution 4.0 International License (http://creativecommons.org/licenses/by/4.0/), which permits unrestricted use, distribution, and reproduction in any medium, provided you give appropriate credit to the original author(s) and the source, provide a link to the Creative Commons license, and indicate if changes were made.

\section{References}

1. K. Osakada and M. Shiomi, International Journal of Machine Tools and Manufacture 46, 1188 (2006).

2. I. Yadroitsev, P. Bertrand and I. Smurov, Applied Surface Science 253, 8064 (2007).

3. J.-P. Kruth, G. Levy, F. Klocke and T. H. C. Childs, CIRP Annals-Manufacturing Technology 56, 730 (2007).

4. T. Kurzynowski, E. Chlebus, B. Kuźnicka, and J. Reiner, in Proceedings of SPIE 8239, High Power Laser Materials Processing: Lasers, Beam Delivery, Diagnostics, and Applications (2012), p. 823914. 
5. G. N. Levy, R. Schindel and J. P. Kruth, CIRP Annals—Manufacturing Technology 52, 589 (2003).

6. L.-C. Zhang and H. Attar, Advanced Engineering Materials 18, 463 (2016).

7. E. O. Ezugwu and Z. M. Wang, Journal of Materials Processing Technology 68, 262 (1997).

8. C. Leyens and M. Peters, Titanium and Titanium Alloys. Fundamentals and Applications, (WileyVCH, Weinheim, 2003), pp. 231-350.

9. L. Thijs, M. L. M. Sistiaga, R. Wauthle, Q. Xie, J.-P. Kruth and J. Van Humbeeck, Acta Materialia 61, 4657 (2013).

10. D. Faidel, D. Jonas, G. Natour and W. Behr, Additive Manufacturing 8, 88 (2015).

11. R. Adams, in Microstructural and Mechanical Property Characterization of Laser Additive Manufactured (LAM) Rhenium. Doctoral Dissertation, Arizona State University (2012).

12. E. Uhlmann, A. Bergmann and W. Gridin, Procedia CIRP 35, 8 (2015).

13. B. Vrancken, L. Thijs, J.-P. Kruth and J. Van Humbeeck, Acta Materialia 68, 150 (2014).

14. E. Chlebus, B. Kuźnicka, R. Dziedzic and T. Kurzynowski, Materials Science and Engineering A 620, 155 (2015).

15. J. C. Williams and E. A. Starke, Acta Materialia 51, 5775 (2003).

16. A. Naor, N. Eliaz, E. Gileadi and S. R. Taylor, AMMTIAC Quarterly 5, 11 (2010).

17. S. F. Kovtun and R. A. Ul'yanov, in Physical Metalurgy of Titanium, ed. I. Kornilov (Science Publishing House, Moscow, 1964), p. 120.

18. T. M. Pollock and S. Tin, Journal of Propulsion and Power 22, 361 (2006).

19. P. Mercelis and J.-P. Kruth, Rapid Prototyping Journal 12, 254 (2006).

20. E. Chlebus, K. Gruber, B. Kuźnicka, J. Kurzac and T. Kurzynowski, Materials Science and Engineering A 639, 647 (2015).

21. W. Z. Friend, Corrosion of Nickel and Nickel-Base Alloys, (Wiley, New York, 1980), p. 435.

22. N. Eliaz, G. Shemesh and R. M. Latanision, Engineering Failure Analysis 9, 31 (2002).

23. I. Gurrappa, Oxidation of Metals 59, 321 (2003).

24. I. Gurappa, Materials Science and Engineering A 356, 372 (2003).

25. M. Anuwar, R. Jayaganthan, V. K. Tewari and N. Arivazhagan, Materials Letters 61, 1483 (2007).

26. Z. Yao and M. Marek, Materials Science and Engineering A 192, 994 (1995).

27. K. Zhang, Z. Li and W. Gao, Materials Letters 57, 834 (2002).

28. E. Godlewska, M. Mitoraj and K. Leszczynska, Corrosion Science 78, 63 (2014).

29. Z. Tang, F. Wang and W. Wu, Intermetallics 7, 1271 (1999).

30. Z. L. Tang, F. H. Wang and W. T. Wu, Oxidation of Metals 51, 235 (1999).

31. G. Liu, M. Li, Y. Zhou and Y. Zhang, Corrosion Science 48, 650 (2006).

32. G. Liu, M. Li, Y. Zhou and Y. Zhang, Journal of the European Ceramic Society 25, 1033 (2005).

33. G. M. Liu, F. Yu, J. H. Tian and J. H. Ma, Materials Science and Engineering A 496, 40 (2008).

34. J. G. Gonzalez-Rodriguez, S. Haro, A. Martinez-Villafañe, V. M. Salinas-Bravo and J. PorcayoCalderon, Materials Science and Engineering A 435-436, 258 (2006).

35. G. Ziółkowski, E. Chlebus, P. Szymczyk and J. Kurzac, Archives of Civil and Mechanical Engineering 14, 608 (2014).

36. D. Gu, Y.-C. Hagedorn, W. Meiners, G. Meng, R. J. Santos Batista, K. Wissenbach and R. Poprawe, Acta Materialia 60, 3849 (2012).

37. M. P. Bacos, M. Thomas, J. L. Raviart, A. Morel, S. Navéos and P. Josso, Materials at High Temperatures 26, 339 (2009).

38. M. Huang and J. Zhu, Rare Metals 35, 127 (2016).

39. Q. Zeng, S. W. Ma, Y. R. Zheng, S. Z. Liu and T. Zhai, Journal of Alloys and Compounds 480, 987 (2009).

40. X. Zhang, H. Deng, S. Xiao, Z. Zhang, J. Tang, L. Deng and W. Hu, Journal of Alloys and Compounds 588, 163 (2014).

41. J. L. Murray, Bulletin of Alloy Phase Diagrams 2, 462 (1982).

42. U. Diebold, Surface Science Reports 48, 53 (2003).

43. E. A. Brandes and G. B. Brook, Smithells Metals Reference Book, 7th ed, (Butterworth-Heinemann, Oxford, 1992), p. 14-1.

44. R. A. Rapp, Corrosion Science 44, 209 (2002).

45. S. Zhao, X. Xie and G. D. Smith, Surface and Coatings Technology 185, 178 (2004).

46. S. G. Bratsch, Journal of Physical and Chemical Reference Data 18, 1 (1989).

47. V. S. Shaldaev, A. N. Malofeeva and A. D. Davydov, Russian Journal of Electrochemistry 50, 994 (2014).

48. J. Bhattarai, Nepal Journal of Science and Technology 10, 109 (2009). 